Article

\title{
Dietary and Health Characteristics of Korean Adults According to the Level of Energy Intake from Carbohydrate: Analysis of the 7th (2016-2017) Korea National Health and Nutrition Examination Survey Data
}

\author{
Sue Min Soh ${ }^{1} \mathbb{D}$, Sang-Jin Chung ${ }^{2} \mathbb{D}$ and Jihyun Yoon ${ }^{1, *}$ \\ 1 Department of Food and Nutrition, Seoul National University, Seoul 08826, Korea; pa2007@snu.ac.kr \\ 2 Department of Foods and Nutrition, Kookmin University, Seoul 02707, Korea; schung@kookmin.ac.kr \\ * Correspondence: hoonyoon@snu.ac.kr
}

Received: 19 December 2019; Accepted: 25 January 2020; Published: 7 February 2020

\begin{abstract}
The purpose of this study was to examine the association between the level of energy intake from carbohydrate and the dietary and health characteristics among Korean adults. We examined the diet quality and health conditions of Korean adults by segmenting them into eight groups according to the level of energy intake from carbohydrate $(<45 \%, 45-50 \%, 50-55 \%, 55-60 \%, 60-65 \%$, $65-70 \%, 70-75 \%$, and $\geq 75 \%$ ). From the data of the 7th (2016-2017) Korea National Health and Nutrition Examination Survey (KNHANES), 7566 subjects aged 19 to 64 years were analyzed. Diet quality was much lower in the groups whose energy intake from carbohydrate was $<50 \%$ or $\geq 65 \%$, compared to the groups whose energy intake from carbohydrate was 50-65\%. Hypertension or low HDL-cholesterolemia was associated with low $(<45 \%)$ or high $(\geq 70 \%)$ energy intake from carbohydrate. We found no considerable difference in the diet quality and health conditions between the groups whose energy intake from carbohydrate was $50-55 \%$ and $55-65 \%$. In conclusion, it is suggested to expand the current acceptable macronutrient distribution range (AMDR) for carbohydrate for Korean adults (i.e., $55 \%$ to $65 \%$ ) to include $50-55 \%$.
\end{abstract}

Keywords: KNHANES; carbohydrate intake; energy intake from carbohydrate

\section{Introduction}

As the intake of animal-source food has increased, energy intake from carbohydrate has continuously decreased among Koreans. The mean of energy intake from carbohydrate of Koreans decreased from $80.3 \%$ in 1969 to $63.6 \%$ in 2017 [1,2]. For the last decade, the proportion of Koreans with less than $55 \%$ of their energy intake from carbohydrate has increased, while the proportion of those with greater than or equal to $70 \%$ of their energy intake from carbohydrate has decreased. As carbohydrate intake recently has become the focus of public attention, low-carbohydrate and high-fat diets which increase fat intake with reducing carbohydrate intake are prevailing for weight loss among some Korean adults. This accelerates the decrease of the energy intake from carbohydrate among Koreans, especially young adults.

According to the Dietary Reference Intakes for Koreans 2015, the current acceptable macronutrient distribution range (AMDR) for carbohydrate is 55 to $65 \%$ for Korean adults [3]. The former AMDR for carbohydrate, which was 55 to $70 \%$ for Korean adults, was revised to 55 to $65 \%$ due to a negative health impact of high carbohydrate intake. The lower limit of the current standard of energy intake from carbohydrate for adults is higher in Korea compared to the United States, Japan, China, and the 
United Kingdom; the current AMDR for carbohydrate is 45 to $65 \%$ in the United States, 50 to $65 \%$ in Japan and China, and 50\% in the United Kingdom for adults [4-7]. Several studies have reported that dietary or health characteristics might be different according to the level of energy intake from carbohydrate [8-13]. The intakes of protein, fat, thiamine, riboflavin, niacin, calcium, phosphorus, and iron were significantly lower in the group whose energy intake from carbohydrate was $>70 \%$, compared to the group whose energy intake from carbohydrate was $55-70 \%$ [8]. In another study, the higher the level of energy intake from carbohydrate, the greater the increase in the number of servings of grains and fruits and the greater the decrease in the number of servings of meat/fish/eggs/legumes and dairy products [9]. Eating above a certain level of carbohydrate has a negative effect on health. For example, as the energy intake from carbohydrate increases, the HDL-cholesterol concentration tends to decrease $[10,11]$. A high carbohydrate intake is associated with metabolic syndrome [11-13].

Although we found a few studies with low carbohydrate intake $[8,12]$, there has been very limited research on energy intake less than 55\% from carbohydrate in Asian population. Moreover, the group with energy intake less than 55\% from carbohydrate was not further segmented, but rather regarded as a single group $[9,14,15]$. As the proportion of Korean adults with energy intake less than $55 \%$ from carbohydrate has increased, we examined the diet quality and health conditions of Korean adults by segmenting them according to their level of energy intake from carbohydrate. Especially, we further segmented the group with energy intake less than $55 \%$ from carbohydrate.

\section{Materials and Methods}

\subsection{Data Source and Subjects}

We used the data from the 7th (2016-2017) Korea National Health and Nutrition Examination Survey (KNHANES). KNHANES is a cross-sectional and nationally representative survey that uses a stratified, multistage sampling method designed for selection of household units. It is administered by the Korea Center for Disease Control and Prevention to identify Korean health and nutrition status. The survey is comprised of three sections: health interview, health examination, and nutrition. The health interview survey and the health examination survey are conducted at the medical check-up vehicles that move around survey areas. The nutrition survey is performed by experienced nutritionists using a one-day 24-h recall method to investigate each respondent's food intake, eating behavior, and food security [16].

Among the 9597 eligible subjects aged 19 to 64 years, the subjects who did not respond to the health interview survey, the health examination survey, or the nutrition survey, and the subjects who reported implausible energy intake ( $<500$ or $>5000 \mathrm{kcal} /$ day) were excluded. Also, a subject who consumed nothing but alcohol was excluded. Consequently, a total of 7566 adults were included in this study and segmented into eight groups by level of energy intake from carbohydrate: less than $45 \%$ ( $<45 \%), 45 \%$ to less than $50 \%(45-50 \%), 50 \%$ to less than $55 \%(50-55 \%), 55 \%$ to less than $60 \%(55-60 \%)$, $60 \%$ to less than $65 \%(60-65 \%), 65 \%$ to less than $70 \%(65-70 \%), 70 \%$ to less than $75 \%(70-75 \%)$, and $75 \%$ or more $(\geq 75 \%)$. In this study, the level of energy intake from carbohydrate was calculated as the percentage of calories from carbohydrate intake out of the total calorie intake.

\subsection{Assessment of Dietary Characteristics}

To assess nutrient adequacy, the nutrient adequacy ratio (NAR) was calculated for protein and eight micronutrients (vitamin A, thiamin, riboflavin, niacin, vitamin C, calcium, phosphorus, and iron). For a given nutrient, the NAR is the ratio of a subject's intake to the recommended nutrient intake (RNI), but limited not to exceed 1 . The nutrient consumed is less than the RNI when the NAR is $<1$; the nutrient consumed is greater than or equal to RNI when the NAR is 1 [17]. To evaluate the overall nutrient intake, the mean adequacy ratio (MAR), which is the mean value of nine NARs, was calculated. A cut-off point of 0.75 was used for NAR and MAR to evaluate the adequacy of nutrient intake [18-21]. The prevalence of subjects who consumed less than the estimated average requirement (EAR) was 
calculated for protein and seven micronutrients (vitamin A, thiamin, riboflavin, niacin, vitamin C, calcium, and iron). In this study, assessment of nutrient intake was performed based on the Dietary Reference Intakes for Koreans 2015 [3]. To assess the food group intake, the dietary diversity score (DDS) and the food group intake patterns were computed based on the method reported by Kant et al. [22,23]. Food items were classified into five major food groups: grains, meat/fish/eggs/legumes, vegetables, fruits, and dairy products. The DDS is the sum of each food group's points, and the food group intake patterns are a combination of a five-digit number with 0 or 1 for each of the food groups in the order of dairy products, meat/fish/eggs/legumes, grains, fruits and vegetables (DMGFV). For each food group, 1 was assigned when more than the minimum amount of a food group was consumed; otherwise, 0 was assigned. For the dairy products and grains, the minimum amount is $15 \mathrm{~g}$ for all solids and $30 \mathrm{~g}$ for all liquids. For meat/fish/eggs/legumes, fruits, and vegetables, the minimum amount is $30 \mathrm{~g}$ for all solids and $60 \mathrm{~g}$ for all liquids.

\subsection{Assessment of Health Characteristics}

We examined the associations of the obesity, hypercholesterolemia, metabolic syndrome, or risk factors of metabolic syndrome with the level of energy intake from carbohydrate. The obesity or hypercholesterolemia criteria were based on the Guidelines for the use of raw data of the 7th (2016-2017) Korea National Health and Nutrition Examination Survey [16]. Metabolic syndrome was classified according to the diagnosis criteria presented in the National Cholesterol Education Program Adult Treatment Panel III [24], with modification of waist circumference cutoff due to the subjects being Korean [25]. Metabolic syndrome was defined if three or more of the following items were present: (1) waist circumference: greater than or equal to $90 \mathrm{~cm}$ for men, greater than or equal to $85 \mathrm{~cm}$ for women; (2) triglycerides: greater than or equal to $150 \mathrm{mg} / \mathrm{dL}$ or in the treatment of related medication; (3) HDL-cholesterol: less than $40 \mathrm{mg} / \mathrm{dL}$ for men, less than $50 \mathrm{mg} / \mathrm{dL}$ for women; (4) blood pressure: systolic blood pressure greater than or equal to $130 \mathrm{mmHg}$, diastolic blood pressure greater than or equal to $85 \mathrm{mmHg}$, or in the treatment of related medication; and (5) fasting glucose: greater than or equal to $110 \mathrm{mg} / \mathrm{dL}$ or in the treatment of related medication.

\subsection{Statistical Analysis}

All statistical analyses were performed using SPSS (version 23.0; IBM Corp., Armonk, NY, USA). As recommended by the Korea Centers for Disease Control and Prevention, this study was performed with a complex sample module including a stratification variable, a clustering variable, and a weight variable [26]. The results are reported as weighted percentage, mean values, and standard errors (SE). The difference between eight groups was tested for statistical significance using Rao-Scott $\chi^{2}$ test or analysis of covariance (ANCOVA) with sex, age, and total energy intake as covariates. Multiple logistic regression was conducted to test association between the level of energy intake from carbohydrate and health conditions. We chose a group whose energy intake from carbohydrate was $60-65 \%$ as a reference for the analysis. A $p$-value $<0.05$ was regarded an indication of statistical significance.

\section{Results}

\subsection{Proportion of Subjects According to the Level of Energy Intake from Carbohydrate}

Figure 1 shows the proportion of subjects according to the level of energy intake from carbohydrate. The highest percentage of subjects, which was $18.2 \%$, was in the group of $60-65 \%$ energy intake from carbohydrate. About $25 \%$ of subjects was in the groups with energy intake less than 55\% from carbohydrate and about $42 \%$ of those were in the groups whose energy intake from carbohydrate was $65 \%$ or more. 


\begin{tabular}{|c|c|c|c|c|c|c|c|}
\hline$<45 \%$ & $45-50 \%$ & $50-55 \%$ & $55-60 \%$ & $60-65 \%$ & $65-70 \%$ & $70-75 \%$ & $\geq 75 \%$ \\
\hline $7.9 \%$ & $6.8 \%$ & $10.6 \%$ & $14.2 \%$ & $18.2 \%$ & $16.6 \%$ & $13.6 \%$ & $12.1 \%$ \\
\hline
\end{tabular}

Figure 1. Proportion of Korean adults aged 19 to 64 years according to the level of energy intake from carbohydrate $(n=7566)$. Note: The data were analyzed using the complex sample module. $<45 \%$ : less than $45 \%$, 45-50\%: $45 \%$ to less than 50\%, 50-55\%: 50\% to less than 55\%, 55-60\%: $55 \%$ to less than $60 \%$, $60-65 \%$ : $60 \%$ to less than $65 \%, 65-70 \%$ : $65 \%$ to less than $70 \%, 70-75 \%$ : $70 \%$ to less than $75 \%$, and $>75 \%$ : $75 \%$ or more.

\subsection{Demographic Characteristics of Subjects}

Table 1 shows the demographic characteristics of the subjects according to the level of energy intake from carbohydrate. The distribution of sex $(p<0.001)$, age $(p<0.001)$, residential area $(p=0.001)$, household income level $(p<0.001)$, education level $(p<0.001)$, employment status $(p=0.017)$, marriage status $(p<0.001)$, and the number of family members $(p<0.001)$ were significantly different among the eight groups by the level of energy intake from carbohydrate.

Table 1. The demographic characteristics of subjects according to the level of energy intake from carbohydrate.

\begin{tabular}{|c|c|c|c|c|c|c|c|c|}
\hline Variable & $\begin{array}{c}<45 \% \\
(n=527)\end{array}$ & $\begin{array}{c}45-50 \% \\
(n=459)\end{array}$ & $\begin{array}{c}50-55 \% \\
(n=740)\end{array}$ & $\begin{array}{c}55-60 \% \\
(n=1037)\end{array}$ & $\begin{array}{c}60-65 \% \\
(n=1342)\end{array}$ & $\begin{array}{c}65-70 \% \\
(n=1281)\end{array}$ & $\begin{array}{c}70-75 \% \\
(n=1116)\end{array}$ & $\begin{array}{c}\geq 75 \% \\
(n=1064)\end{array}$ \\
\hline & \multicolumn{8}{|c|}{$(\%)$} \\
\hline Male & 59.2 & 54.2 & 53.3 & 51.3 & 52.0 & 51.7 & 45.2 & 41.1 \\
\hline Female & 40.8 & 45.8 & 46.7 & 48.7 & 48.0 & 48.3 & 54.8 & 58.9 \\
\hline Age (years) & \multicolumn{8}{|c|}{$p<0.001$} \\
\hline $30-49$ & 48.6 & 49.0 & 49.8 & 51.2 & 49.9 & 49.7 & 40.9 & 35.4 \\
\hline $50-64$ & 17.0 & 17.8 & 19.0 & 23.6 & 28.0 & 35.3 & 43.9 & 58.4 \\
\hline Residential area & \multicolumn{8}{|c|}{$p=0.001$} \\
\hline Urban & 90.3 & 90.4 & 90.5 & 88.7 & 87.1 & 87.5 & 85.7 & 83.7 \\
\hline Rural & 9.7 & 9.6 & 9.5 & 11.3 & 12.9 & 12.5 & 14.3 & 16.3 \\
\hline Medium-high & 28.5 & 29.6 & 31.3 & 34.4 & 33.7 & 31.5 & 33.1 & 27.4 \\
\hline High & 43.0 & 42.7 & 39.7 & 37.5 & 36.6 & 36.1 & 32.9 & 29.4 \\
\hline $\begin{array}{l}\text { Education level }{ }^{1} \\
(n=7224)\end{array}$ & \multicolumn{8}{|c|}{$p<0.001$} \\
\hline$\leq$ Elementary school graduate & 1.5 & 2.1 & 2.0 & 3.6 & 4.2 & 5.9 & 8.5 & 18.0 \\
\hline Middle school graduate & 4.1 & 3.6 & 5.1 & 5.4 & 4.7 & 9.4 & 9.8 & 14.4 \\
\hline High school graduate & 40.4 & 35.6 & 40.4 & 36.6 & 38.3 & 37.8 & 38.0 & 35.4 \\
\hline$\geq$ College graduate & 54.0 & 58.7 & 52.4 & 54.4 & 52.8 & 46.9 & 43.8 & 32.1 \\
\hline $\begin{array}{l}\text { Employment status }{ }^{1} \\
(n=7219)\end{array}$ & \multicolumn{8}{|c|}{$p=0.017$} \\
\hline Employed & 27.9 & 29.5 & 33.9 & 29.0 & 28.6 & 28.5 & 30.9 & 35.9 \\
\hline 3 & 32.1 & 33.3 & 33.1 & 30.2 & 29.6 & 28.8 & 33.2 & 28.4 \\
\hline 4 & 34.9 & 28.1 & 33.1 & 35.4 & 33.9 & 33.7 & 29.1 & 28.2 \\
\hline$\geq 5$ & 6.4 & 9.6 & 7.3 & 9.9 & 10.0 & 10.7 & 10.3 & 9.9 \\
\hline
\end{tabular}

Notes: The data were analyzed using the complex sample module. $p$-value by Rao-Scott $\chi^{2}$ test. ${ }^{1}$ Different from the total number of subjects due to the missing data. $<45 \%$ : less than $45 \%, 45-50 \%$ : $45 \%$ to less than $50 \%$, 50-55\%: $50 \%$ to less than 55\%, 55-60\%: 55\% to less than 60\%, 60-65\%: $60 \%$ to less than $65 \%, 65-70 \%$ : $65 \%$ to less than $70 \%$, $70-75 \%: 70 \%$ to less than $75 \%$, and $\geq 75 \%$ : $75 \%$ or more. 
Unlike the other groups, the percentage of women was higher than that of men in the groups whose energy intake was $70-75 \%$ or $\geq 75 \%$. Subjects aged 19 to 29 years were more likely to have lower carbohydrate intake, whereas those aged 50 to 64 years were more likely to have higher carbohydrate intake. The percentage of those with higher household income or with higher than college graduate showed lower energy intake from carbohydrate.

\subsection{Dietary Characteristics}

Table 2 shows the NARs and MARs of Korean adults according to the level of energy intake from carbohydrate. The NARs of protein $(p<0.001)$, vitamin A $(p<0.001)$, thiamin $(p<0.001)$, riboflavin $(p<0.001)$, niacin $(p<0.001)$, vitamin C $(p<0.001)$, calcium $(p<0.001)$, phosphorus $(p<0.001)$, iron $(p=0.022)$, and MARs $(p<0.001)$ were significantly different among the eight groups. The NARs of vitamin A, vitamin $C$, and calcium were below 0.75 in all groups. The NARs of riboflavin and niacin were below 0.75 only in the group whose energy intake from carbohydrate was $\geq 75 \%$. The MAR was below 0.75 only in the groups whose energy intake from carbohydrate was $70-75 \%$ or $\geq 75 \%$.

The NARs of vitamin A and calcium were lowest in the group whose energy intake from carbohydrate was $\geq 75 \%$, and the NAR of vitamin C was lowest in the group whose energy intake from carbohydrate was $<45 \%$. The MAR was lowest in the group whose energy intake from carbohydrate was $\geq 75 \%$, followed by the group of $70-75 \%$ energy intake from carbohydrate.

Figure 2 shows the prevalence of Korean adults who consumed less than the EAR of protein and selected micronutrients according to the level of energy intake from carbohydrate. The prevalence of adults with insufficient intakes of protein, vitamin A, thiamin, riboflavin, niacin, vitamin $C$, and calcium was significantly different among the eight groups $(p<0.001)$, but this was not the case for iron. The prevalence of those with insufficient intake of vitamin A, vitamin $C$, or calcium was higher than $50 \%$ in all groups. The prevalence of adults with insufficient intake of vitamin A or calcium was highest in the group whose energy intake from carbohydrate was $\geq 75 \%$, and those with insufficient intake of vitamin $C$ was highest in the group whose energy intake from carbohydrate was $<45 \%$. The prevalence of adults with insufficient intake of other nutrients such as protein, thiamin, riboflavin, and niacin tended to increase as the level of energy intake from carbohydrate increased, and it was highest in the group whose energy intake from carbohydrate was $\geq 75 \%$.

Table 3 shows the DDS and its distribution for Korean adults according to the level of energy intake from carbohydrate. The DDS was significantly different among the eight groups $(p<0.001)$. The DDS was lowest in the group whose energy intake from carbohydrate was $\geq 75 \%$. The DDS was significantly lower in the groups whose energy intake from carbohydrate was $<45 \%$ or $\geq 75 \%$, compared to the groups whose energy intake from carbohydrate was 50-55\%, 55-60\%, 60-65\%, or 65-70\%. The group of $45-50 \%$ energy intake from carbohydrate showed a lower DDS compared to the group of 55-60\% energy intake from carbohydrate.

The group whose energy intake from carbohydrate was 70-75\% showed a lower DDS compared to the two groups whose energy intake from carbohydrate was 55-60\% or 60-65\%. As the level of energy intake from carbohydrate increased, the DDS tended to increase until the energy intake from carbohydrate was 55-60\% and 60-65\%, whereas it tended to decrease after those levels. The distribution of DDS was significantly different among the eight groups $(p<0.001)$. The percentage of adults with DDS of 5 was much lower in the groups whose energy intake from carbohydrate was $<50 \%$ or $\geq 75 \%$, compared to the others. 
Table 2. Nutrient adequacy ratio (NAR) and mean adequacy ratio (MAR) of Korean adults according to the level of energy intake from carbohydrate.

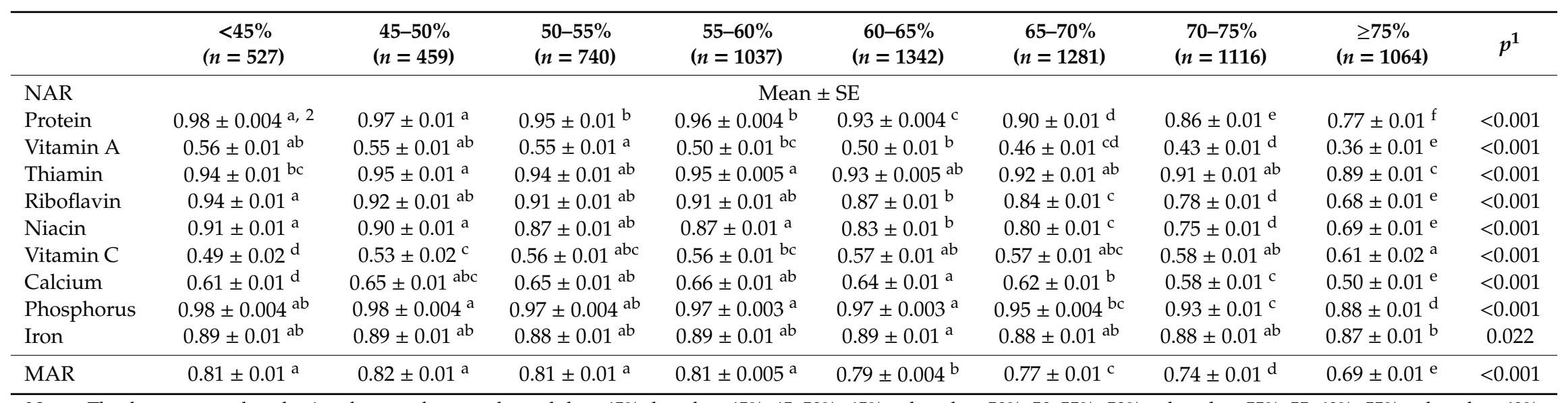

Notes: The data were analyzed using the complex sample module. $<45 \%$ : less than $45 \%, 45-50 \%$ : $45 \%$ to less than $50 \%, 50-55 \%: 50 \%$ to less than $55 \%$, $55-60 \%$ : $55 \%$ to less than $60 \%$, 60-65\%: $60 \%$ to less than $65 \%, 65-70 \%: 65 \%$ to less than $70 \%, 70-75 \%: 70 \%$ to less than $75 \%$, and $\geq 75 \%: 75 \%$ or more. ${ }^{1}$ For the NAR of protein and the MAR by ANCOVA with sex and age as covariates. For NARs of vitamins and minerals by ANCOVA with total energy intake in addition to sex and age. ${ }^{2}$ Post-hoc test: Holm-Bonferroni, $a>b>c>d>e ~ f$.

Table 3. The dietary diversity score and its distribution of Korean adults according to the level of energy intake from carbohydrate.

\begin{tabular}{|c|c|c|c|c|c|c|c|c|c|}
\hline & $\begin{array}{c}<45 \% \\
(n=527)\end{array}$ & $\begin{array}{c}45-50 \% \\
(n=459)\end{array}$ & $\begin{array}{c}50-55 \% \\
(n=740)\end{array}$ & $\begin{array}{c}55-60 \% \\
(n=1037)\end{array}$ & $\begin{array}{c}60-65 \% \\
(n=1342)\end{array}$ & $\begin{array}{c}65-70 \% \\
(n=1281)\end{array}$ & $\begin{array}{c}70-75 \% \\
(n=1116)\end{array}$ & $\begin{array}{c}\geq 75 \% \\
(n=1064)\end{array}$ & $p^{2}$ \\
\hline \multirow[t]{2}{*}{ DDS $^{1}$} & \multicolumn{8}{|c|}{ Mean \pm SE } & \multirow{3}{*}{$<0.001$} \\
\hline & $3.72 \pm 0.03^{\mathrm{d}, 3}$ & $3.81 \pm 0.04^{\mathrm{bcd}}$ & $3.88 \pm 0.04^{a b c}$ & $3.97 \pm 0.03^{a}$ & $3.96 \pm 0.03^{\mathrm{ab}}$ & $3.92 \pm 0.03^{a b c}$ & $3.90 \pm 0.03^{\mathrm{cd}}$ & $3.75 \pm 0.03^{e}$ & \\
\hline DDS $^{1}$ & \multicolumn{8}{|c|}{$\%$} & \\
\hline 1 & 0.4 & 0.1 & 0.3 & 0.3 & 0.2 & 0.3 & 0.3 & 0.4 & \multirow{5}{*}{$<0.001$} \\
\hline 2 & 1.5 & 1.1 & 2.8 & 1.6 & 0.8 & 1.5 & 2.8 & 5.4 & \\
\hline 3 & 38.5 & 35.2 & 29.9 & 26.5 & 29.4 & 29.0 & 26.7 & 29.4 & \\
\hline 4 & 44.8 & 44.8 & 42.9 & 44.0 & 42.1 & 44.4 & 46.4 & 48.6 & \\
\hline 5 & 14.9 & 18.8 & 24.1 & 27.6 & 27.4 & 24.9 & 23.8 & 16.2 & \\
\hline
\end{tabular}

Notes: The data were analyzed using the complex sample module. $<45 \%$ : less than $45 \%$, 45-50\%: $45 \%$ to less than $50 \%, 50-55 \%$ : 50\% to less than $55 \%, 55-60 \%$ : $55 \%$ to less than $60 \%$, 60-65\%: 60\% to less than 65\%, 65-70\%: 65\% to less than 70\%, 70-75\%: 70\% to less than 75\%, and $\geq 75 \%$ : 75\% or more. ${ }^{1}$ Dietary diversity score. ${ }^{2}$ By Rao-Scott $\chi^{2}$ test or ANCOVA with sex and age as covariates. ${ }^{3}$ Post-hoc test: Holm-Bonferroni, a $>\mathrm{b}>\mathrm{c}>\mathrm{d}>\mathrm{e}$. 


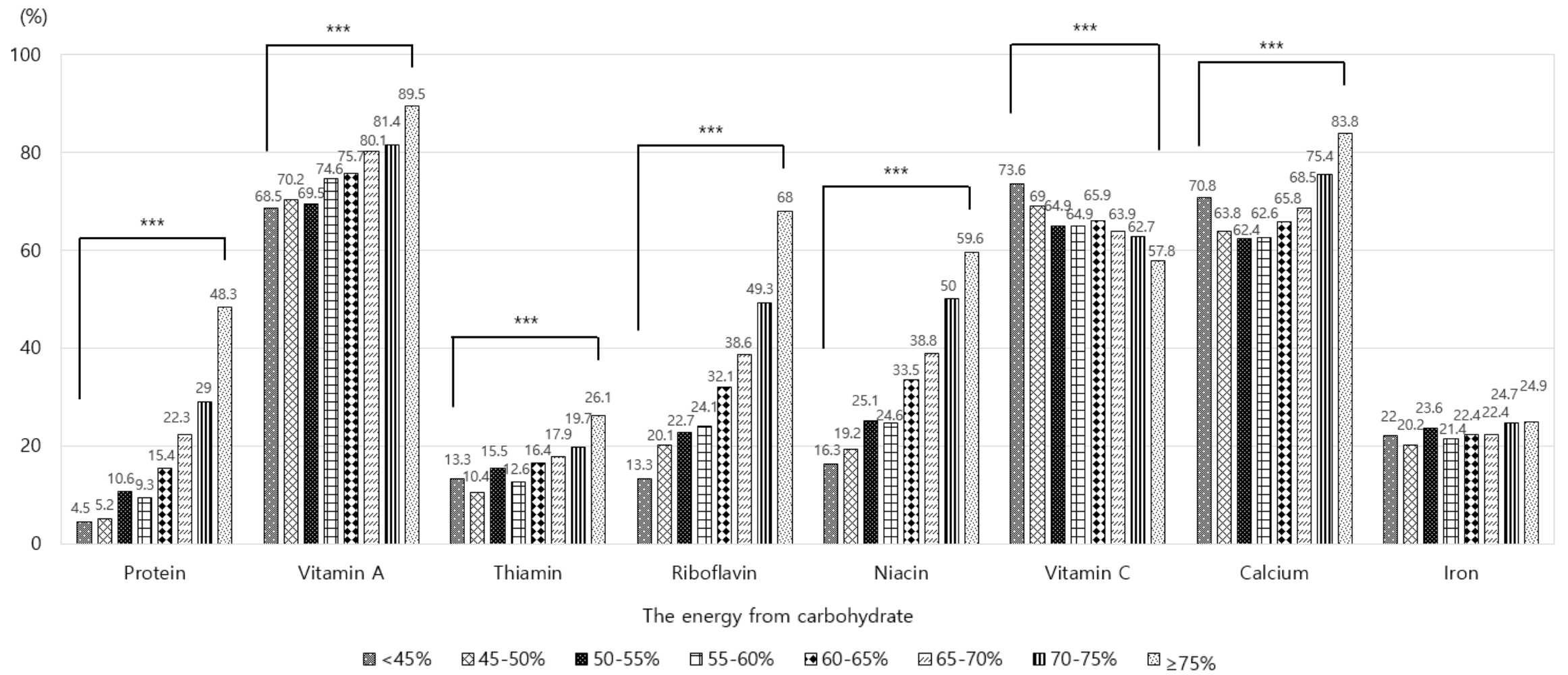

Figure 2. Percentage of Korean adults with insufficient nutrient intakes according to the level of energy intake from carbohydrate. Note: The data were analyzed using the complex sample module. <45\%: less than $45 \%$, 45-50\%: $45 \%$ to less than $50 \%$, 50-55\%: $50 \%$ to less than $55 \%$, 55-60\%: 55\% to less than $60 \%$, $60-65 \%$ : $60 \%$ to less than $65 \%, 65-70 \%$ : $65 \%$ to less than $70 \%, 70-75 \%$ : $70 \%$ to less than $75 \%$, and $>75 \%$ : $75 \%$ or more. The values are the percentages of those who consumed nutrients less than estimated average requirements. ${ }^{* *}$ Significantly different between eight groups at $p<0.001$ by Rao-Scott $\chi^{2}$ test. 
Table 4 shows the food group intake patterns in Korean adults according to the level of energy intake from carbohydrate. The food group intake patterns were significantly different among the eight groups $(p<0.001)$. The percentage of those who consumed less than minimum amount of both dairy products and fruits was much higher in the groups whose energy intake from carbohydrate was $<45 \%$ or $45-50 \%$, compared to the others. The percentage of those who consumed less than the minimum amount of dairy products was much higher in the groups whose energy intake from carbohydrate was $65-70 \%, 70-75 \%$ and $\geq 75 \%$ compared to the others, which was about $42 \%$ of subjects in the group of $\geq 75 \%$ energy intake from carbohydrate. The nutrient and food group intakes of Korean adults according to the level of energy intake from carbohydrate are presented in Tables S1 and S2, respectively.

Table 4. The food group intake patterns of Korean adults according to the level of energy intake from carbohydrate.

\begin{tabular}{|c|c|c|c|c|c|c|c|c|c|}
\hline & $\begin{array}{c}<45 \% \\
(n=527)\end{array}$ & $\begin{array}{c}45-50 \% \\
(n=459)\end{array}$ & $\begin{array}{c}50-55 \% \\
(n=740)\end{array}$ & $\begin{array}{c}55-60 \% \\
(n=1037)\end{array}$ & $\begin{array}{c}60-65 \% \\
(n=1342)\end{array}$ & $\begin{array}{c}65-70 \% \\
(n=1281)\end{array}$ & $\begin{array}{c}70-75 \% \\
(n=1116)\end{array}$ & $\begin{array}{c}\geq 75 \% \\
(n=1064)\end{array}$ & $p^{2}$ \\
\hline DMGFV $^{1}$ & \multicolumn{8}{|c|}{$\%$} & \multirow{4}{*}{$<0.001$} \\
\hline 01111 & 24.8 & 22.0 & 23.2 & 26.5 & 25.7 & 31.0 & 34.6 & 41.8 & \\
\hline 11101 & 18.6 & 21.9 & 19.3 & 17.2 & 15.8 & 12.0 & 10.2 & 3.5 & \\
\hline 01101 & 35.9 & 32.9 & 28.1 & 25.6 & 27.8 & 27.2 & 25.1 & 19.9 & \\
\hline
\end{tabular}

Note: The data were analyzed using the complex sample module. $<45 \%$ : less than $45 \%, 45-50 \%$ : $45 \%$ to less than $50 \%, 50-55 \%: 50 \%$ to less than $55 \%, 55-60 \%: 55 \%$ to less than $60 \%, 60-65 \%: 60 \%$ to less than $65 \%, 65-70 \%: 65 \%$ to less than $70 \%, 70-75 \%: 70 \%$ to less than $75 \%$, and $\geq 75 \%: 75 \%$ or more. ${ }^{1}$ D: dairy products, M: meat/fish/eggs/legumes, G: grains, F: fruits, V: vegetables. In order of DMGFV, when more of each food group was consumed, 1 was assigned; otherwise, 0 was assigned. ${ }^{2}$ By Rao-Scott $\chi^{2}$ test.

\subsection{Health Characteristics}

Table 5 shows the association of the energy intake from carbohydrate with obesity, hypercholesterolemia, metabolic syndrome or risk factors of metabolic syndrome among Korean adults after adjusting for age, sex and total energy intake. For low HDL-cholesterolemia, the group whose energy intake from carbohydrate was $\geq 75 \%$ showed an OR of 1.37 (95\% CI, 1.10-1.70). For hypertension, the group whose energy intake from carbohydrate was $<45 \%$ showed an OR of $1.48(1.10-2.00)$ and the group whose energy intake from carbohydrate was 70-75\% showed an OR of 1.25 (1.00-1.55). However, the associations of the energy intake from carbohydrate with obesity, hypercholesterolemia, metabolic syndrome, high waist circumference, hypertriglyceridemia, or impaired fasting glucose were not significant. The blood biochemical indices of Korean adults according to the level of energy intake from carbohydrate are presented in Table S3. 
Table 5. The health characteristics of Korean adults according to the level of energy intake from carbohydrate. ${ }^{1 .}$

\begin{tabular}{|c|c|c|c|c|c|c|c|c|}
\hline & $\begin{array}{c}<45 \% \\
(n=527)\end{array}$ & $\begin{array}{l}45-50 \% \\
(n=459)\end{array}$ & $\begin{array}{l}50-55 \% \\
(n=740)\end{array}$ & $\begin{array}{c}55-60 \% \\
(n=1037)\end{array}$ & $\begin{array}{c}60-65 \% \\
(n=1342)\end{array}$ & $\begin{array}{c}65-70 \% \\
(n=1281)\end{array}$ & $\begin{array}{c}70-75 \% \\
(n=1116)\end{array}$ & $\begin{array}{c}\geq 75 \% \\
(n=1064)\end{array}$ \\
\hline & \multicolumn{8}{|c|}{ OR $(95 \% \text { CI })^{2}$} \\
\hline Obesity $^{3}(n=7559)$ & $1.25(0.97-1.61)$ & $1.15(0.88-1.50)$ & $1.11(0.90-1.37)$ & $1.14(0.93-1.40)$ & Reference & $0.98(0.80-1.21)$ & $0.89(0.73-1.08)$ & $1.05(0.85-1.29)$ \\
\hline Hypercholesterolemia $^{3}(n=7205)$ & $0.89(0.65-1.21)$ & $0.87(0.60-1.26)$ & $0.97(0.72-1.31)$ & $0.81(0.62-1.06)$ & Reference & $0.81(0.64-1.03)$ & $0.79(0.61-1.02)$ & $0.86(0.68-1.10)$ \\
\hline Metabolic syndrome $^{3,4}(n=7334)$ & $1.06(0.79-1.42)$ & $0.98(0.69-1.40)$ & $1.14(0.86-1.53)$ & $0.88(0.68-1.15)$ & Reference & $0.99(0.79-1.24)$ & $0.98(0.76-1.27)$ & $1.10(0.86-1.40)$ \\
\hline \multicolumn{9}{|l|}{$\begin{array}{l}\text { Risk factors of metabolic } \\
\text { syndrome }^{3,5}(n=7334)\end{array}$} \\
\hline High waist circumference & $1.16(0.88-1.52)$ & $1.12(0.84-1.50)$ & $1.16(0.91-1.49)$ & $1.09(0.87-1.36)$ & Reference & $0.98(0.79-1.22)$ & $1.05(0.84-1.32)$ & $1.05(0.83-1.32)$ \\
\hline Hypertriglyceridemia & $1.03(0.81-1.30)$ & $1.23(0.92-1.63)$ & $1.13(0.90-1.44)$ & $1.07(0.86-1.34)$ & Reference & $1.10(0.91-1.33)$ & $1.00(0.81-1.24)$ & $1.14(0.92-1.40)$ \\
\hline Low HDL-cholesterolemia & $1.00(0.78-1.28)$ & $0.89(0.66-1.19)$ & $1.07(0.85-1.35)$ & $1.13(0.91-1.39)$ & Reference & $1.18(0.97-1.43)$ & $1.20(0.98-1.47)$ & $1.37(1.10-1.70)^{* *}$ \\
\hline Hypertension & $1.48(1.10-2.00) * *$ & $1.20(0.89-1.61)$ & $1.16(0.91-1.48)$ & $0.97(0.77-1.22)$ & Reference & $0.96(0.79-1.18)$ & $1.25(1.00-1.55)$ * & $1.10(0.87-1.38)$ \\
\hline Impaired fasting glucose & $0.96(0.66-1.40)$ & $0.94(0.63-1.40)$ & $1.05(0.73-1.50)$ & $0.83(0.62-1.12)$ & Reference & $0.99(0.76-1.29)$ & $1.01(0.77-1.31)$ & $1.10(0.86-1.41)$ \\
\hline $\begin{array}{l}{ }^{*} p<0.05,{ }^{* *} p<0.005 . \text { Note: } \mathrm{Th} \\
\text { to less than } 60 \%, 60-65 \%: 60 \% \\
\text { adjusted for sex, age, and total } \\
\text { of metabolic syndrome. }{ }^{5} \mathrm{High} \\
150 \mathrm{mg} / \mathrm{dL} \text { or in the treatment }\end{array}$ & are analvze & $\begin{array}{l}\text { o, CI: confi } \\
\text { than or eq } \\
\text { DDL-choles }\end{array}$ & $\begin{array}{l}\mathrm{cm} \text { for mer } \\
\text { a (less than }\end{array}$ & $\begin{array}{l}\text { eater than or } \\
d L \text { for men a }\end{array}$ & $\begin{array}{l}\text { to } 85 \mathrm{~cm} \\
\mathrm{~s} \text { than } 50\end{array}$ & $\begin{array}{l}\text { an } 50 \%, 50-5 \\
\text { ore. }{ }^{1} \text { Result } \\
\text { e to missing } \\
\text { men), hypert } \\
\text { for women) }\end{array}$ & $\begin{array}{l}0 \% \text { to less than } \\
\text { ltiple logistic r } \\
\text { Having three } \\
\text { eridemia (grea } \\
\text { ertension (syst }\end{array}$ & $\begin{array}{l}55-60 \%: 55 \% \\
\text { ssion analysis } \\
\text { re risk factors } \\
\text { an or equal to } \\
\text { lood pressure } \\
\text { reater than or }\end{array}$ \\
\hline
\end{tabular}




\section{Discussion}

The current AMDR of energy intake from carbohydrate for adults is 55 to $65 \%$ in Korea, 50 to $65 \%$ in Japan, 45 to 65\% in the United States, and 50\% in the United Kingdom [3-5,7]. The mean energy intake from carbohydrate among adults is higher in Korea compared to the other countries mentioned above; it was $64.0 \%$ in Korea, $57.7 \%$ in Japan, $47.0 \%$ in the United States, and $45.7 \%$ in the United Kingdom [2,27-29]. However, carbohydrate intake has been decreased dramatically among Koreans due to westernized diet, which was related to increase the risk of being overweight or obesity [30,31]. In reality, our study showed that the percentage of those with energy intake less than 55\% from carbohydrate was $25.3 \%$, which is more than six times higher than 11 years ago. A study using the data from the 3rd (2005) KNHANES reported that the percentage of those with energy intake less than 55\% from carbohydrate among subjects aged 20 to 69 years was 4.1\% [14]. Therefore, it would be necessary to identify appropriate AMDR that reflects current carbohydrate intake of Koreans.

We examined the association of diet quality and health conditions with the level of energy intake from carbohydrate, and found that we could suggest possibly to add 50-55\% energy intake from carbohydrate as revised AMDR into current one for carbohydrate in Korean adults. In this study, we further segmented categories of carbohydrate intake according to the level of energy intake from carbohydrate $(<45 \%, 45-50 \%, 50-55 \%, 55-60 \%, 60-65 \%, 65-70 \%, 70-75 \%$, and $\geq 75 \%)$ to explore the possibility of AMDR expansion for carbohydrate in Korean adults.

Recently, some studies have reported that high and low energy intake from carbohydrate is associated with the high mortality [32,33]. According to a study which analyzed the data from the Atherosclerosis Risk in Communities (ARIC) study, there was a U-shaped association of energy intake from carbohydrate and mortality, and the risk of mortality was lowest when energy intake from carbohydrate was 50\% to 55\%, which implies that both high and low energy intake from carbohydrate is associated with increased mortality [32]. Our results also showed that hypertension was more likely to be present at both high (70-75\%) and low (<45\%) energy intake from carbohydrate, and low HDL-cholesterolemia was more likely to be present at high $(\geq 75 \%)$ energy intake from carbohydrate, compared to the reference group whose energy intake from carbohydrate was $60-65 \%$.

Many studies have examined the relationship between carbohydrate intake and obesity, metabolic syndrome, hypertriglyceridemia, low HDL-cholesterolemia, hypertension, or impaired fasting glucose. In accordance with our study, a high carbohydrate intake was associated with low HDL-cholesterolemia in the previous studies [11,12,14,34]. A study with subjects aged 19 years or older reported that the odds ratio for low HDL-cholesterolemia of those in the highest quintile of energy intake from carbohydrate was 1.31 in men and 1.45 in women compared to the lowest quintile of energy intake from carbohydrate [11]. Another study including subjects aged 40 to 69 years reported that the odds ratio for low HDL-cholesterolemia of those in the highest quartile of the energy intake from carbohydrate was 1.23 compared to the lowest quartile of energy intake from carbohydrate [12].

Several studies reported that high carbohydrate intake was associated with metabolic syndrome or its risk factors, such as hypertriglyceridemia in men or women [9,11-13,15,34-36]. Obesity was also reported to be associated with high carbohydrate intake due to continued elevation of blood insulin [37]. However, the link between carbohydrate intake and hypertension or impaired fasting glucose was unclear $[8,9,11,14,38]$. Being hypertensive with high carbohydrate intake in our results may be associated with high sodium intake by fermented vegetable in Koreans' traditional carbohydrate-rich diet or kidney related mechanisms by insufficient vitamin A consumption, not with carbohydrate intakes themselves $[39,40]$. We did not find the association between carbohydrate intake and obesity, hypercholesterolemia or metabolic syndrome. However, this might be due to using moderate carbohydrate intake (60-65\% energy intake from carbohydrate) as a reference to compare groups in our study, whereas most studies used lowest or highest quartile as a reference. Further studies are needed to clarify the relation of the carbohydrate intake to the aforementioned risk factors.

In our study, the MAR was below 0.75 in the groups whose energy intake from carbohydrate was $\geq 70 \%$, indicating that overall nutrient intake was inadequate. The NARs of vitamin A and calcium 
were lowest in the group whose energy intake from carbohydrate was $\geq 75 \%$, and the NAR of vitamin $\mathrm{C}$ was lowest in the group whose energy intake from carbohydrate was $<45 \%$. These results are similar with a study which segmented the subjects into two groups according to the level of energy intake from carbohydrate, 55-70\% and $>70 \%$ [8]. According to that study, the MAR was below 0.75 only in the group whose energy intake from carbohydrate was $>70 \%$. The NARs of vitamin A, riboflavin, vitamin $\mathrm{C}$, and calcium were below 0.75 in both the groups. Also, the NARs of vitamin A, thiamin, riboflavin, niacin, and calcium were significantly lower in the group whose energy intake from carbohydrate was $>70 \%$, compared to the other group. In summary, the NARs of some selected nutrients or the MAR were lower in the groups whose energy intake from carbohydrate was $<45 \%$ or $\geq 70 \%$, compared to the others in our study. The reason for the difference of MARs among eight groups could be due to the different micronutrients intakes by changes of the level of energy intake from protein or fat, which was affected by various levels of energy intake from carbohydrate.

In the present study, the prevalence of those who consumed less than the EAR for each of vitamin A, vitamin C, and calcium was more than $50 \%$ in all groups. This indicates that many Korean adults inadequately consumed those nutrients regardless of the level of energy intake from carbohydrate. Above all, the prevalence of those with insufficient intake of vitamin A or calcium was highest in the group whose energy intake from carbohydrate was $\geq 75 \%$, and those with insufficient intake of vitamin $\mathrm{C}$ was highest in the group whose energy intake from carbohydrate was $<45 \%$. Meat/fish/eggs/legumes intake has been reported to have a $15 \%$ or more contribution to vitamin A intake in the Korean population [41], and it is inversely associated with the carbohydrate intake [9]. Therefore, this could be the reason why the prevalence of those with insufficient intake of vitamin A tended to increase as the level of energy intake from carbohydrate increased. Vitamin $C$ is mostly consumed by eating vegetables or fruits and the major sources of calcium are dairy products in Korea [3]. A study which analyzed the data from the 6th (2013-2015) KNHANES reported that the number of servings of fruits tended to increase whereas the number of servings of dairy products tended to decrease as the level of energy intake from carbohydrate increased [9]. Therefore, this might be the reason why the prevalence of those with insufficient intake of vitamin $C$ tended to decrease and that of calcium tended to increase as the level of energy intake from carbohydrate increased. In summary, the prevalence of those who inadequately consumed vitamin A, vitamin C, or calcium was highest at either the group whose energy intake from carbohydrate was $<45 \%$ or the group whose energy intake from carbohydrate was $\geq 75 \%$.

The percentage of subjects with a DDS of 5 in our study was lower in the groups whose energy intake from carbohydrate was $<50 \%$ or $\geq 75 \%$, compared to the others. The percentage of those who consumed less dairy products than the minimum amount was higher in the groups whose energy intake from carbohydrate was $\geq 65 \%$, compared to the others. The possible explanation for this result is as follows. According to the previous studies, the dairy product intake tended to decrease as the level of energy intake from carbohydrate increased [9,42]. A study using the data from the 6th (2013-2015) KNHANES reported that a higher energy intake from carbohydrate was associated with less consumption of dairy products. For the dairy products, the ratio of the number of servings to the recommended number of servings tended to decrease as the level of energy intake from carbohydrate increased [9]. Another study of a Japanese population aged 40 to 70 years also reported that the dairy products intake significantly decreased as the level of energy intake from carbohydrate increased [42]. In summary, the food group intake was more inadequate in the groups whose energy intake from carbohydrate was $<50 \%$ or $\geq 65 \%$, compared to the others.

There are few studies which examine the association between various levels of energy intake from carbohydrate and risk factors such as metabolic syndrome, hypertriglyceridemia, low HDL-cholesterolemia, hypertension, or diabetes mellitus. In our study, no considerable difference was found in metabolic risk factors and diet quality between the groups of $50-55 \%$ and $55-65 \%$ energy intake from carbohydrate.

Our study has some limitations. First, we used a cross-sectional study design, which cannot draw any causal relationships. Second, the results might be different from subjects' usual daily intake as 
we used the dietary data that were obtained using a 24-h recall method. The results presented in our study should be interpreted with consideration of these limitations.

\section{Conclusions}

The diet quality was much lower in the groups of $<50 \%$ or $\geq 65 \%$ energy intake from carbohydrate, compared to the groups of 50-65\% energy intake from carbohydrate. The odds ratio for low HDL-cholesterolemia or hypertension was significantly higher in the groups of $<45 \%$ or $\geq 70 \%$ energy intake from carbohydrate, compared to the group of 60-65\% energy intake from carbohydrate. We found no considerable difference in the diet quality and health conditions between the groups of $50-55 \%$ and 55-65\% energy intake from carbohydrate. Therefore, this study suggests to expand the current AMDR for carbohydrate to $50-65 \%$ for Korean adults by adding $50-55 \%$ to the current range of $55-65 \%$. Further cohort studies regarding the causal relationship between the level of energy intake from carbohydrate and health conditions could provide additional information for elucidating the optimal level of energy intake from carbohydrate for Korean adults.

Supplementary Materials: The following are available online at http://www.mdpi.com/2072-6643/12/2/429/s1, Table S1: The nutrient intake of Korean adults according to the level of energy intake from carbohydrate, Table S2: The food group intake of Korean adults according to the level of energy intake from carbohydrate, Table S3: The biochemical indices of Korean adults according to the level of energy intake from carbohydrate.

Author Contributions: Conceptualization, S.M.S.; Data curation, S.M.S.; Formal analysis, S.M.S.; Methodology, S.M.S. and J.Y.; Project administration, J.Y.; Validation, S.-J.C. and J.Y.; Visualization, S.-J.C.; Writing-original draft, S.M.S. and J.Y.; Writing-review and editing, S.-J.C. All authors have read and agreed to the published version of the manuscript.

Funding: This research received no external funding.

Conflicts of Interest: The authors declare no conflict of interest.

\section{References}

1. The Ministry of Health and Welfare; The Korea Centers for Disease Control and Prevention. Korea Health Statistics 2007; Korea Centers for Disease Control and Prevention: Seoul, Korea, 2009; p. 37.

2. The Ministry of Health and Welfare; The Korea Centers for Disease Control and Prevention. Korea Health Statistics 2017; Korea Centers for Disease Control and Prevention: Cheongju, Korea, 2019; p. 133.

3. The Ministry of Health and Welfare; The Korean Nutrition Society. Dietary Reference Intakes for Koreans 2015; The Korean Nutrition Society: Sejong, Korea, 2015; pp. 241, 361, 386, 405, 434, 571, 660, 713, 945-949.

4. Institute of Medicine. Dietary Reference Intakes: The Essential Guide to Nutrient Requirements; The National Academies Press: Washington, DC, USA, 2006; p. 70.

5. Dietary Reference Intakes for Japanese. Available online: https://www.mhlw.go.jp (accessed on 25 February 2019).

6. Dietary Reference Intakes for Chinese. Available online: https://www.cnsoc.org/ (accessed on 25 February 2019).

7. Nutrition Requirements. Available online: https://www.nutrition.org.uk/attachments/article/907/Nutrition\% 20Requirements_Revised\%20August\%202019.pdf (accessed on 5 March 2019).

8. Park, M.S.; Suh, Y.S.; Chung, Y. Comparison of chronic disease risk by dietary carbohydrate energy ratio in Korean elderly: Using the 2007-2009 Korea National Health and Nutrition Examination Survey. J. Nutr. Health 2014, 47, 247-257. [CrossRef]

9. Lee, Y.J.; Song, S.; Song, Y. High-carbohydrate diets and food patterns and their associations with metabolic disease in the Korean population. Yonsei Med. J. 2018, 59, 834-842. [CrossRef] [PubMed]

10. Choi, H.; Song, S.; Kim, J.; Chung, J.; Yoon, J.; Paik, H.Y.; Song, Y. High carbohydrate intake was inversely associated with high-density lipoprotein cholesterol among Korean adults. Nutr. Res. 2012, 32, 100-106. [CrossRef]

11. Ha, K.; Kim, K.; Chun, O.K.; Joung, H.; Song, Y. Differential association of dietary carbohydrate intake with metabolic syndrome in the US and Korean adults: Data from the 2007-2012 NHANES and KNHANES. Eur. J. Clin. Nutr. 2018, 72, 848-860. [CrossRef] 
12. Cho, N.H.; Cho, A.K.; Kim, H.K.; Kim, J.B.; Lee, K.E.; Kim, S.S.; Kim, Y.; Jang, H.C.; Baik, I. Carbohydrate composition associated with the 2-year incidence of metabolic syndrome in Korean adults. Clin. Nutr. Res. 2017, 6, 122-129. [CrossRef]

13. Feng, R.; Du, S.; Chen, Y.; Zheng, S.; Zhang, W.; Na, G.; Li, Y.; Sun, C. High carbohydrate intake from starchy foods is positively associated with metabolic disorders: A cohort study from a Chinese population. Sci. Rep. 2015, 5, 1-8. [CrossRef]

14. Park, S.H.; Lee, K.S.; Park, H.Y. Dietary carbohydrate intake is associated with cardiovascular disease risk in Korean: Analysis of the third Korea National Health and Nutrition Examination Survey (KNHNES III). Int. J. Cardiol. 2010, 139, 234-240. [CrossRef]

15. Song, S.; Lee, J.E.; Song, W.O.; Paik, H.Y.; Song, Y. Carbohydrate intake and refined-grain consumption are associated with metabolic syndrome in the Korean adult population. J. Acad. Nutr. Diet. 2014, 114, 54-62. [CrossRef]

16. Guidelines for the use of raw data of the 7th (2016-2017) Korea National Health and Nutrition Examination Survey. Available online: https://knhanes.cdc.go.kr/knhanes/sub03/sub03_02_02.do (accessed on 1 February 2019).

17. Guthrie, H.A.; Scheer, J.C. Validity of a dietary score for assessing nutrient adequacy. J. Am. Diet. Assoc. 1981, 78, 240-245.

18. Lee, J.; Hyun, W.; Kwak, C.; Kim, C.; Lee, H. Relationship between the number of different food consumed and nutrient intakes. Korean J. Community Nutr. 2000, 5, 297-306.

19. Shim, J.E.; Paik, H.Y.; Lee, S.Y.; Moon, H.K.; Kim, Y. Comparative analysis and evaluation of dietary intake of Koreans by age groups: (4) The Korean diet quality index. Korean J. Nutr. 2002, 35, 558-570.

20. Koszewski, W.; Behrends, D.; Nichols, M.; Sehi, N.; Jones, G. Patterns of family meals and food and nutrition intake in limited resource families. Fam. Consum. Sci. Res. J. 2011, 39, 431-441. [CrossRef]

21. Kim, H.; Kwon, S.; Lee, J.; Choi, Y.; Chung, H.R.; Kwak, T.; Park, J.; Kang, M. Development of a Nutrition Quotient (NQ) equation modeling for children and the evaluation of its construct validity. Korean J. Nutr. 2012, 45, 390-399. [CrossRef]

22. Kant, A.K.; Block, G.; Schatzkin, A.; Ziegler, R.G.; Nestle, M. Dietary diversity in the US population, NHANES II, 1976-1980. J. Am. Diet. Assoc. 1991, 91, 1526-1531.

23. Kant, A.K.; Schatzkin, A.; Block, G.; Ziegler, R.G.; Nestle, M. Food group intake patterns and associated nutrient profiles of the US population. J. Am. Diet. Assoc. 1991, 91, 1532-1537.

24. Expert panel on detection, evaluation, and treatment of high blood cholesterol in adults. Executive summary of the third report of the national cholesterol education program (NCEP) expert panel on detection, evaluation, and treatment of high blood cholesterol in adults (Adult Treatment Panel III). J.A.M.A. 2001, 285, 2486-2497. [CrossRef]

25. Korean Endocrine Society; Korean Society for the Study of Obesity. Management of Obesity, 2010 Recommendation. Endocrinol. Metab. 2010, 25, 301-304. [CrossRef]

26. Guidelines for raw data analysis of the Korea National Health and Nutrition Examination Survey (SPSS). Available online: https://knhanes.cdc.go.kr/knhanes/sub03/sub03_06_02.do (accessed on 5 February 2019).

27. The National Health and Nutrition Survey in Japan, 2017. Available online: https://www.mhlw.go.jp/content/ 000451755.pdf (accessed on 18 July 2019).

28. What We Eat in America, NHANES 2015-2016. Available online: https:/www.ars.usda.gov/ARSUserFiles/ 80400530/pdf/1516/Table_5_EIN_GEN_15.pdf (accessed on 18 July 2019).

29. National Diet and Nutrition Survey: Results from Years 7 and 8 (combined) of the Rolling Programme (2014/2015 to 2015/2016). Available online: https://www.gov.uk/government/statistics/ndns-results-fromyears-7-and-8-combined (accessed on 25 February 2019).

30. Song, S.; Shim, J.E. Trends in dietary intake of total fat and fatty acids among Korean adolescents from 2007 to 2017. Nutrients 2019, 11, 3073. [CrossRef]

31. Song, Y.; Park, M.J.; Paik, H.Y.; Joung, H. Secular trends in dietary patterns and obesity-related risk factors in Korean adolescents aged 10-19 years. Int. J. Obes. 2010, 34, 48-56. [CrossRef]

32. Seidelmann, S.B.; Claggett, B.; Cheng, S.; Henglin, M.; Shah, A.; Steffen, L.M.; Folsom, A.R.; Rimm, E.B.; Willett, W.C.; Solomon, S.D. Dietary carbohydrate intake and mortality: A prospective cohort study and meta-analysis. Lancet Public Health 2018, 3, e419-e428. [CrossRef] 
33. Fung, T.T.; van Dam, R.M.; Hankinson, S.E.; Stampfer, M.; Willett, W.C.; Hu, F.B. Low-carbohydrate diets and all-cause and cause-specific mortality: two cohort studies. Ann. Intern. Med. 2010, 153, 289-298. [CrossRef]

34. Song, S.; Song, W.O.; Song, Y. Dietary carbohydrate and fat intakes are differentially associated with lipid abnormalities in Korean adults. J. Clin. Lipidol. 2017, 11, 338-347. [CrossRef]

35. Kim, K.; Yun, S.H.; Choi, B.Y.; Kim, M.K. Cross-sectional relationship between dietary carbohydrate, glycemic index, glycemic load and risk of the metabolic syndrome in a Korean population. Br. J. Nutr. 2008, 100, 576-584. [CrossRef]

36. Radhika, G.; Van Dam, R.M.; Sudha, V.; Ganesan, A.; Mohan, V. Refined grain consumption and the metabolic syndrome in urban Asian Indians (Chennai Urban Rural Epidemiology Study 57). Metabolism. 2009, 58, 675-681. [CrossRef]

37. Sartorius, K.; Sartorius, B.; Madiba, T.E.; Stefan, C. Does high-carbohydrate intake lead to increased risk of obesity? A systematic review and meta-analysis. B. M. J. Open 2018, 8, e018449. [CrossRef]

38. Nanri, A.; Mizoue, T.; Noda, M.; Takahashi, Y.; Kato, M.; Inoue, M.; Tsugane, S. Rice intake and type 2 diabetes in Japanese men and women: The Japan Public Health Center-based Prospective Study. Am. J. Clin. Nutr. 2010, 92, 1468-1477. [CrossRef]

39. Lee, J.Y.; Cho, D.S.; Kim, H.J. The effect of salt usage behavior on sodium intake and excretion among Korean women. Nutr. Res. Pract. 2012, 6, 232-237. [CrossRef]

40. Danquah, I.; Dobrucky, C.L.; Frank, L.K.; Henze, A.; Amoako, Y.A.; Bedu-Addo, G.; Raila, J.; Schulze, M.B.; Mockenhaupt, F.P.; Schweigert, F.J. Vitamin A: potential misclassification of vitamin A status among patients with type 2 diabetes and hypertension in urban Ghana. Am. J. Clin. Nutr. 2015, 102, 207-214. [CrossRef]

41. Kim, S.; Jun, S.; Joung, H. Estimated dietary intake of vitamin A in Korean adults: Based on the Korea National Health and Nutrition Examination Survey 2007 2012. J. Nutr. Health 2016, 49, 258-268. [CrossRef]

42. Horikawa, C.; Yoshimura, Y.; Kamada, C.; Tanaka, S.; Tanaka, S.; Matsunaga, S.; Hanyu, O.; Araki, A.; Ito, H.; Tanaka, A.; et al. Is the proportion of carbohydrate intake associated with the incidence of diabetes complications?-An analysis of the Japan Diabetes Complications Study. Nutrients 2017, 9, 113. [CrossRef]

(C) 2020 by the authors. Licensee MDPI, Basel, Switzerland. This article is an open access article distributed under the terms and conditions of the Creative Commons Attribution (CC BY) license (http://creativecommons.org/licenses/by/4.0/). 